\title{
Evaluation of leishmanicidal activity and cytotoxicity of Ricinus communis and Azadirachta indica extracts from western Kenya: in vitro and in vivo assays
}

Bernard N. Jumba ${ }^{1,7,8}$, Christopher O. Anjili², Judith Makwali ${ }^{1}$, Johnstone Ingonga ${ }^{2}$, Rose Nyamao ${ }^{3}$, Sylvia Marango ${ }^{1}$, Joseph K. Choge ${ }^{5}$ and Christopher Khayeka-Wandabwa ${ }^{2,4,6^{*}}$

\begin{abstract}
Background: Despite advances to targeted leishmanicidal chemotherapy, defies around severe toxicity, recent emergence of resistant variants and absence of rational vaccine still persist. This necessitates search and/or progressive validation of accessible medicinal remedies including plant based. The study examined both in vivo and in vitro response of L. major infection to combined therapy of Ricinus communis and Azadirachta indica extracts in BALB/C mice as the mouse model. A comparative study design was applied.

Results: $\mathrm{BALB} / \mathrm{C}$ mice, treated with combination therapy resulted in significantly $(p<0.05)$ larger reduction of lesion than those treated with monotherapies. The spleno-somatic index was found to be significantly low with combination therapy than monotherapies. Antiparasitic effect of $A$. indica and $R$. communis on amastigote with a $50 \%$ inhibitory concentration $\left(I C_{50}\right)$ was of 11.5 and $16.5 \mu \mathrm{g} \mathrm{mL}^{-1}$ respectively while combination therapy gave $9.0 \mathrm{\mu g} \mathrm{ml}^{-1}$ compared to the standard drugs, Pentostam and amphotericin B which had an $\mathrm{IC}_{50}$ of 6.5 and $4.5 \mathrm{\mu g} \mathrm{ml}^{-1}$ respectively. Optimal efficacy of $A$. indica and R. communis was 72 and $59.5 \%$ respectively, combination therapy gave $88 \%$, while Pentostam and amphotericin B had 98 and $92 \%$ respectively against amastigotes. Against promastigotes $A$. indica and $R$. Communis gave an $\mathrm{IC}_{50}$ of $10.1,25.5 \mu \mathrm{g} \mathrm{mL}{ }^{-1}$ respectively, while combination, $12.2 \mu \mathrm{g} \mathrm{mL}^{-1}$ against 4.1 and $5.0 \mathrm{mg} \mathrm{ml}^{-1}$ for Pentostam and amphotericin B respectively. The optimal efficacy of the compounds against promastigotes was 78.0, 61.5 and $91.2 \%$ (A. indica, $R$. communis and A. indica $+R$. communis respectively) against 96.5 and $98 \%$ for Pentostam and amphotericin B respectively. The concentrations at optimal efficacy were significantly different $(p<0.05)$ among the test compounds. An evaluation of the $I_{50}$ values of the combination therapies clearly reveals synergistic effects.
\end{abstract}

Conclusion: Combination therapy of A. indica and R. communis had best antileishmanial activity than the monotherapies. The active ingredients of both $R$. communis and $A$. indica need to be fractionated, and studied further for activity against Leishmania parasites.

Keywords: Leishmaniasis, Ricinus communis, Azadirachta indica, Leishmania major, Pentostam, Amphotericin B, Combination therapy, 50 \% inhibitory concentration, Toxic, Efficacy, In vitro and in vivo

\footnotetext{
*Correspondence: christorwan@gmail.com

${ }^{6}$ African Population and Health Research Center (APHRC),

P.O. Box 10787-00100, Nairobi, Kenya

Full list of author information is available at the end of the article
} 


\section{Background}

In many tropical and subtropical developing countries, protozoan parasites are amongst the most common infectious agents and have serious consequences for socio-economic development [1, 2]. The World Health Organization (WHO) considers leishmaniasis to be one of the most serious parasitic diseases and the World Health Assembly has advocated a concertation for its control [3]. Due to species differences in tissue tropism, virulence and their interaction with the host's immune system, infection by leishmaniasis can result in a variety of clinical manifestations ranging from single self-healing ulcers in cutaneous forms to life threatening visceral infections $[4,5]$. The pentavalent antimonials sodium stibogluconate and meglumine antimoniate alongside their generics have been the first-line treatment for leishmaniases in many areas for decades [6-8]. Albeit, antimonials are considered to be toxic with frequent, sometimes life-threatening, adverse side effects. Patients under the age of 2 or aged $\geq 45$ with signs of advanced disease and/ or severe malnutrition are at higher risk of death during therapy owing to drug toxicity, slowness of drug action, infection complications or a combination of these factors [9-11]. Although there is still a need for more research and development (R\&D) to improve the drug pipeline for leishmaniasis [12], some alternatives have become available in recent years. The most pressing research needs for leishmaniasis control are the search for alternative and cost effective drugs for oral, parenteral or topical administration in shorter treatment cycles, and identification of mechanisms to facilitate access to existing control measures, including health-sector reform in some developing countries. These will help mitigate the neglected tropical disease (NTDs) associated chronic vicious cycle of poverty in sub-Saharan Africa and other contexts with high prevalence.

The castor oil plant, Ricinus communis is a species of flowering plant in the spurge family, Euphorbiaceae. It belongs to a monotypic genus, Ricinus, and sub-tribe, Ricininae. Alcoholic extract of the leaf has been shown to be hepatoprotective in rats [13]. Methanolic extracts of the leaves of $R$. communis have shown antimicrobial properties [14]. The pericarp of castor bean showed central nervous system effects in mice at low doses. Antihistamine and anti-inflammatory properties have been found in ethanolic extract of $R$. communis root bark [15]. The neem tree, Azadirachta indica, A. Juss (Meliaceae) is an Indian tree that has many useful compounds that act as insecticide. It has also been documented to have anti-leishmanial effect on L. donovani [16]. However, little information is available on efficacy of combination therapy of $A$. indica and $R$. communis.
Considering conventional targeted leishmanicidal chemotherapy options are out of reach for most rural communities in developing countries, alternatives are bound to be sort or incorporated in rational management of the complication. Evidently, many of these populations and individually held knowledge by the traditional health practitioners (THP) know a lot about medicinal flora that can cure a diversity of diseases while combination of medicinal remedies by the herbalists/self-prescription is now a common occurrence [17-20], but due to a number of protocols required, their effective use remain speculative. There are limited studies available interrogating the anti-parasite properties on synergistic, antagonistic or toxicity effect of combined medicinal therapies in various medical conditions. Furthermore, efficacy of plant extracts is known to be affected by among other things; location, amount of active compounds in the plants, extraction procedure and species of organism under study; which makes it very difficult to generalize the antiparasitic/pathogenic properties of many plant species. In light of this, especially in the tropical regions where there are large forested land under these plants, the aim of this study was to assess response of Leishmania major to combined therapy of $R$. communis and $A$. indica extracts in BALB/c mice.

\section{Methods}

\section{Experimental design}

The in vivo and in vitro studies were carried out using a comparative study design. The efficacy and toxicity of samples were compared with those of Pentostam (GlaxoSmithKline, UK) and amphotericin B [Fungizone ${ }^{\mathrm{TM}}$, $\mathrm{X}$-Gen Pharmaceuticals (US)]. In vivo studies were further subjected to a complete randomized block design. The results were compared to determine the efficacy of the test samples against the known standard drugs for treating leishmaniasis.

\section{Anti-leishmanial plants and extracts}

The plant extracts were obtained from the $A$. indica and $R$. communis. Leaves of $A$. indica and $R$. communis were collected from Kakamega forest Western region of Kenya with the assistance of a plant taxonomist and their voucher specimens were deposited at the East African Herbarium, National Museums of Kenya, Nairobi, Kenya (Ricinus communis TFm13 and Azadirachta indica TFm23). The plant extracts were processed according to the method of Kigondu et al. [21]. The plant parts were chopped into small pieces; air dried at room temperature $\left(25^{\circ} \mathrm{C}\right)$ for 14 days and pulverized using a laboratory mill (Christy \& Norris Ltd., Chelmsford, England). $1 \mathrm{~kg}$ of each powder was soaked in absolute methanol for 3 days 
to extract compounds. The extract was filtered, dried with $\mathrm{Na}_{2} \mathrm{SO}_{4}$ and the solvent removed under vacuum in a rotary evaporator at $30-35{ }^{\circ} \mathrm{C}$. For aqueous extraction, $100 \mathrm{~g}$ of ground material in $600 \mathrm{ml}$ of water was placed in a water bath and maintained at $60{ }^{\circ} \mathrm{C}$ for $2 \mathrm{~h}$. This filtrate was freeze dried (using a Freeze Dryer, Edwards freeze dryer Modulyo), weighed and stored at $-20{ }^{\circ} \mathrm{C}$ until required for use. DMSO was used in all the drug formulations because it has been reported to increase drug penetration [22]. These methanolic extracts were used for anti-leishmanial testing. The plant yields for $A$. indica and $R$. communis were $15-18 \% \mathrm{w} / \mathrm{w}$ and $10-15 \% \mathrm{w} / \mathrm{w}$ of plant leaves respectively.

\section{Mice and parasites}

Female 8 week old BALB/c mice weighing $20 \pm 2$ g were used in the experiment. The animals were obtained from Kenya Medical Research Institute (KEMRI) animal breeding facility, Nairobi-Kenya. The animals were moved into the experimental room for acclimatization one week before the start of the experiments. The mice were housed in $15 \mathrm{~cm} \times 21 \mathrm{~cm} \times 29 \mathrm{~cm}$ transparent plastic cages. They were fed with pellets (Mice pellets $\mathrm{UNGA}^{\circledR}$ feeds) and water ad libitum.

Leishmania major (strain IDUB/KE/83 = NLB-144) which was originally isolated in 1983 from a female $P$. duboscqi collected near Marigat, Baringo County Kenya was used [23]. The L. major strain was maintained by serial passage in $\mathrm{BALB} / \mathrm{c}$ mice to maintain virulence. An aspirate isolate from the footpad of infected BALB/C mouse was cultivated in Schneider's Drosophila insect medium (Sigma, Saint Louis, USA), supplemented with $20 \%$ heat inactivated foetal bovine serum (FBS) (Cultilab, Campinas, SP, Brazil), $500 \mu \mathrm{g} / \mathrm{ml}$ penicillin, $500 \mu \mathrm{g} / \mathrm{ml}$ streptomycin and $250 \mu \mathrm{g} / \mathrm{ml} 5$-fluorocytosine arabinoside (all from Gibco, Grand Island, NY, USA) [24, 25]. Promastigotes were incubated at $25{ }^{\circ} \mathrm{C}$ grown to stationary phase to generate infective metacyclic forms at 6 th day of culture. Promastigotes in the medium were counted with a hemocytometer (Improved Double Neubauer) (Pharmacia-GE Healthcare, Uppsala, Sweden) with a Nikon optiphot optical microscope at $40 \times$ magnification.

\section{In vitro studies}

\section{Cytotoxicity assay}

In vitro cytotoxicity assay was carried out following a modified rapid colorimetric assay as previously described by Mosmann [26]. Vero cells were cultured and maintained in Eagle's Minimum Essential Medium (MEM) supplemented with $10 \%$ FBS. The cells were cultured at $37{ }^{\circ} \mathrm{C}$ in $5 \% \mathrm{CO}_{2}$ for $24 \mathrm{~h}$, harvested by trypsinization, pooled in a $50 \mathrm{ml}$ vial and $100 \mu \mathrm{l}$ cell suspension $\left(1 \times 10^{6}\right.$ cells $\left./ \mathrm{ml}\right)$ put into 2 wells of rows $\mathrm{A}-\mathrm{H}$ in a 96-well micro titer Nunc-Immuno ${ }^{\mathrm{TM}}$ (MaxiSorp $^{\mathrm{TM}}$ Surface) plate, the medium aspirated off and $150 \mu$ l of the highest concentration of the $A$. indica and $R$. communis added into the same row and serial dilution. The controls used were cells with no extract and medium alone. MTT (3-4, 5-dimethgylthiaol-2-yl-2, 5-diphenyltetrazolium bromide) reagent $(10 \mu \mathrm{l})$ was added into each well and the cells incubated for $4 \mathrm{~h}$. After which, the medium together with MTT were aspirated off. Dimethylsulfoxide (DMSO) $(100 \mu \mathrm{l})$ was added and the plates shaken for $5 \mathrm{~min}$. The absorbance was measured for each well at $562 \mathrm{~nm}$ using a micro-titre plate reader [27].

\section{Minimum inhibitory concentration (MIC) and anti-promastigotes assay}

Leishmania major promastigotes $\left(10^{6}\right.$ parasites $\left./ \mathrm{ml}\right)$ was incubated at $26{ }^{\circ} \mathrm{C}$ for $120 \mathrm{~h}$ in fresh media (brain heart infusion medium), supplemented with $10 \%$ FBS in the absence or presence of serial concentrations (100, 50, 25, $12.5,6.25$ and $3.125 \mu \mathrm{g} / \mathrm{ml}$ ) of the extracts. Cell growth was determined daily by assessment of visible turbidity. The MIC was considered as the lowest concentration of each substance used that inhibited more than $99 \%$ of $L$. major growth in vitro.

Promastigotes were incubated in 24-well plates in the presence of serial concentrations of the extracts for $120 \mathrm{~h}$. Aliquots of parasites were then transferred to 96-well Nunc-Immuno $^{\text {TM }}$ (MaxiSorp ${ }^{\text {TM }}$ Surface) microtiter plate, incubated at $27{ }^{\circ} \mathrm{C}$ in $5 \% \mathrm{CO}_{2}$ for $24 \mathrm{~h}$, then $100 \mu \mathrm{l}$ of highest concentration of the extract was added and serially diluted, then incubated further at $27^{\circ} \mathrm{C}$ for $48 \mathrm{~h}$. The controls used were promastigotes with no extract and medium alone. MTT reagent $(10 \mu \mathrm{l})$ was added and incubated for $4 \mathrm{~h}$, then the medium together with MTT was aspirated off; DMSO $(100 \mu \mathrm{l})$ was added and the plates were shaken gently for $5 \mathrm{~min}$. The absorbance was measured for each well at $562 \mathrm{~nm}$ using a micro-titer plate reader [26].

\section{Macrophage cultures for anti-amastigote assay and determination of nitric oxide}

Four days after intraperitoneal injection of female BALB/c mice (8-12 week old; Kenya Medical Research Institute (KEMRI) animal breeding facility, NairobiKenya) with $4 \%$ Brewer's thioglycolate broth (Difco, Inc., Detroit, MI), peritoneal macrophages were harvested with Phosphate-buffered saline (PBS) and processed as described [28, 29]. The derived macrophages were infected with $L$. major stationary phase promastigotes at a 6:1 parasite/macrophage ratio. Uninfected macrophages were used as negative controls. Infected macrophages were incubated at $37^{\circ} \mathrm{C}$ in $5 \% \mathrm{CO}_{2}$ for $4 \mathrm{~h}$. After incubation, the remaining extracellular parasites 
were removed by gentle washing and the cultures incubated in RPMI (JRH Biosciences, Lenexa, KS) for 24 h. Subsequently, treatment of infected macrophages with the $R$. communis and A. indica was done as earlier described [30,31].The medium replenishment was for 3 days (24, 48 and $72 \mathrm{~h}$ time points). Pentostam and amphotericin $\mathrm{B}$ were used as a positive control drugs for comparison of parasite inhibition. On day four, the wells were washed twice with normal saline and the reaction was stopped by adding stop solution, then incubated for $2 \mathrm{~h}$, washed twice with normal saline and fixed with methanol then stained with Giemsa stain. The infection levels were determined by counting the percentage of infected cells and the number of amastigotes per 100 macrophages [30]. This analysis was performed by two independent observers who were blinded to the experimental conditions. After each time point, supernatants were harvested and stored at $-70{ }^{\circ} \mathrm{C}$ for analysis of nitric oxide (NO) production. Nitrite $\left(\mathrm{NO}_{2}^{-}\right)$accumulation in the cell culture supernatants was used as an indicator of NO production and was determined by a standard Griess reaction $[28,29,32]$.

\section{In vivo; experimental infections setup, treatment, lesion measurement and parasite burden}

For in vivo settings, the sample size was calculated using the resource equation method [33]. $48 \mathrm{BALB} / \mathrm{c}$ mice were inoculated with $1 \times 10^{6}$ stationary phase $L$. major promastigotes in $50 \mu \mathrm{l}$ phosphate buffered saline into the Left Hind Footpad (LHFP) using a 29 gauge needle and left for 4 weeks incubation period [34]. The inoculated mice were then randomly assigned into 6 groups of 8 mice in each. Group 1 treated with $A$. indica extracts, group 2 with $R$. communis, group 3 with combination of A. indica $(10 \mathrm{ml} / \mathrm{kg})$ and $R$. communis $(15 \mathrm{ml} / \mathrm{kg})$, group 4 with sterile PBS, group 5 Pentostam and group 6 amphotericin $\mathrm{B}$; treatment commenced on the 5 th week post infection (day 29), for 28 days [34-36]. All treatments were done intraperitoneally.

A total of four mice per group were sampled at week 10 for analysis of $L$. major parasite loads. Lesion size, which was defined as the difference in thickness between the infected footpad and the non-infected contralateral Footpad, was monitored weekly by measurement using a Starret dial caliper (Mitutoyo, Suzano, SP, and Brazil) [37, 38]. The weight of the mice was also monitored on a weekly basis. The spleen were removed and weighed and changes post-infection and chemotherapy were determined based on spleno-somatic indices as previously described [39]. Splenic L. major burdens were determined from Giemsa-stained impression smears and expressed as Leishman-Donovan units (the number of amastigotes per 1000 host nuclei, multiplied by the weight of the organ); (a) LDU $=$ No. of parasites $/ 1000$ host nuclei; (b) Total $\mathrm{LDU}=\mathrm{LDU} \times$ organ weight $\times 2 \times 10^{5}[32,40,41]$.

\section{Ethical clearance}

All procedures were per the Kenya Medical Research Institute (KEMRI) operational and approved protocols under the bioprospecting for plant based anti-leishmanial compounds programme/theme as regulated by the Scientific Steering Committee (SSC), Ethical Review Committee (ERC) and Animal Care and Use committee (ACUC). The guidelines were strictly adhered to during the research.

\section{Statistical analysis}

The data collected on lesion sizes, parasite loads and absorbance were analyzed using the SPSS software. All experiments were performed in triplicate, the mean standard deviation of at least three experiments were determined, statistical analysis of the differences between mean values obtained for the experimental groups was done by the students $t$ test. $P$ values of 0.05 or less were considered to be significant. To determine the efficacy range of the chemical dosages used, a logistical model which can be used to identify non-linear response to ranges of concentrations was fitted to the data. The logit model: $\operatorname{logit}[\theta(\mathrm{x})]=\log \left[\theta^{(\mathrm{x})} / 1-\theta(\mathrm{x})\right]=\beta_{0}+\beta_{1} \mathrm{x}_{1}+\beta$ ${ }_{2} \mathrm{x}_{2}+\ldots \beta_{\mathrm{i}} \mathrm{x}_{\mathrm{i}}$ is a general logistic model which takes the form $\log [\rho / 1-\rho]=\beta_{0}+\beta_{1} C+\beta_{2} C^{2}+\beta_{3}+C^{3}$ in dose response treatments [42]; where $\rho$ denotes the probability of survival, $\beta_{0}$ is an intercept, $\beta_{1}$ is the coefficient of concentration $C$, and $\beta_{2}$ is the coefficient of quadratic response in $C$ while $\beta_{3}$ is the coefficient of cubic response in C. All analyzed results were declared significant at $p<0.05$.

\section{Results}

Results indicating the cell viability of the Vero-E6 cells subjected to the test drugs are shown in Fig. 1. The VeroE6 cells were significantly affected by treatment using the test drugs of $A$. indica, $R$. communis and $A$. indica $+R$. communis $(p<0.05)$. The concentration of the test drug required to destroy $50 \%$ of the mammalian cell was significantly low in $R$. communis $(92 \mu \mathrm{g} / \mathrm{mL})$ followed by $A$. indica $+R$. communis $(101 \mu \mathrm{g} / \mathrm{mL})$ and highest in treatment using A. indica $(149 \mu \mathrm{g} / \mathrm{mL})$.

The promastigotes growth was significantly affected by the various plant extracts $(p<0.05)$ after exposure. The $\%$ growth inhibition estimated for the promastigote form of parasite fully fitted the logistic regression model (Table 1). Based on the model parameter coefficients of $\mathrm{C}$, the most effective drug against promastigotes was Amphotericin B followed by Pentostam which are standard drugs for leishmaniasis. Among the extracts 


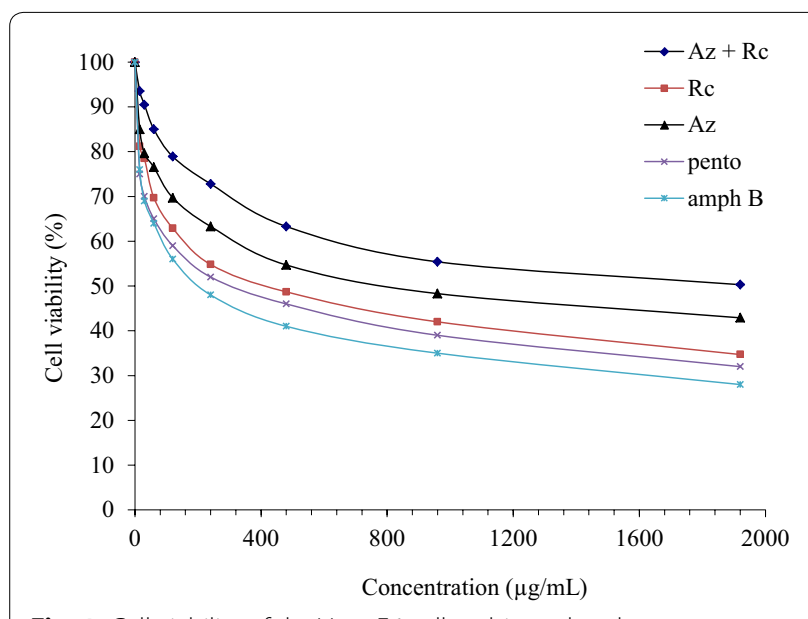

Fig. 1 Cell viability of the Vero-E6 cells subjected to the test extracts

the combined therapy of $A$. indica and $R$. communis was found to be the most effective drugs followed by $A$. indica while $R$. communis was the least effective. The efficacy of different concentrations of $R$. communis, A. indica, $A$. indica $+R$. communis and standard drugs Pentostam and Amphotericin B on promastigotes of L. major is shown in Fig. 2. The optimal efficacy, concentration at optimal efficacy, $\mathrm{IC}_{90}, \mathrm{IC}_{50}$ of the extracts and standard drugs against promastigote forms of the parasite are shown in Table 2. There were significant differences in the optimal efficacy of the test drugs $(p<0.05)$. The optimal efficacy of the standard drugs was 98 and $96.5 \%$ for amphotericin $\mathrm{B}$ and Pentostam respectively. Among the test extracts, combined therapy of $A$. indica and $R$. communis was the most effective against promastigote followed by $A$. indica while $R$. communis was the least effective. There was significant $(p<0.05)$ differences in the $\mathrm{IC}_{50}$ with the lowest $\mathrm{IC}_{50}$ occurring in $A$. indica $+R$. communis, followed by $A$. indica and least in $R$. communis among the known standard test drugs.

The efficacy of different concentrations of plant extracts and standard drugs, on amastigotes of L. major is presented in Fig. 3. The amastigote growth was significantly affected by the various test plant extracts $(p<0.05)$ of exposure. The $\%$ growth inhibition estimated for the

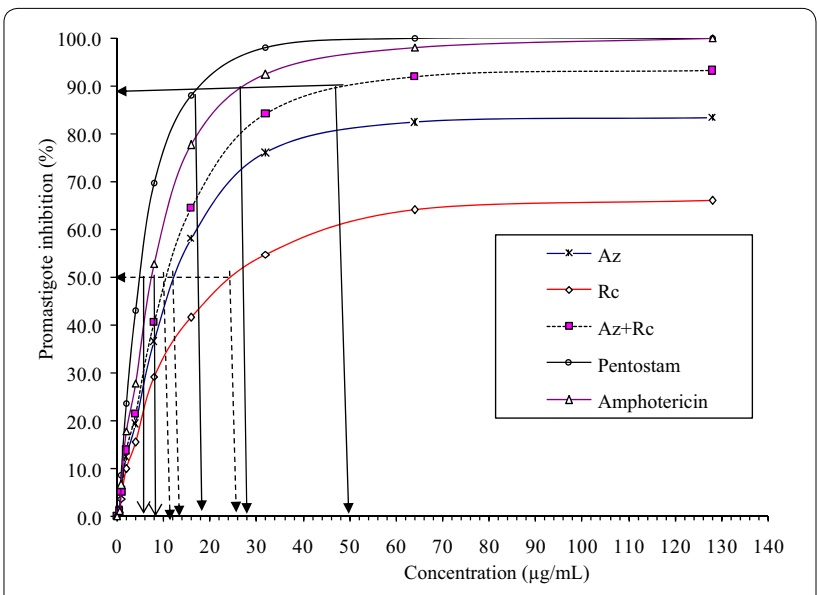

Fig. 2 Promastigote growth inhibition following treatments with various test extracts

amastigote form of parasite fully fitted the logistic regression model (Table 3). Based on the model parameter coefficients of $\mathrm{C}$, the most effective drug was amphotericin B followed by Pentostam, which were standard drugs. Among the test drugs that were used in the current study, the combined therapy of $A$. indica $+R$. communis was found to be the most effective drugs followed by $A$. indica then $R$. communis. The optimal efficacy, concentration at optimal efficacy, $\mathrm{IC}_{90}, \mathrm{IC}_{50}$ of the test drugs against amastigote forms of the parasites are described in Table 4. The optimal efficacy of the extracts was $72,59.5$ and $88 \% A$. indica, $R$. communis and combination of $A$. indica and $R$. communis respectively, compared to standard drugs that had 98 and $92 \%$ for Pentostam and amphotericin B respectively. Only combined therapy of $A$. indica $+R$. communis $(34.5 \mu \mathrm{g} / \mathrm{mL})$ achieved $\mathrm{IC}_{90}$ compared to the test drugs which had $15.5 \mu \mathrm{g} / \mathrm{ml}, 24.5 \mu \mathrm{g} / \mathrm{ml}$, for Pentostam and ampotericin $B$ respectively. There was significant $(p<0.05)$ difference in the $\mathrm{IC}_{50}$ with the lowest $\mathrm{IC}_{50}$ occuring in $A$. indica $+R$. communis, followed by $A$. indica and least in $R$. communis among the known standard test drugs.

The nitric oxide production in macrophages of BALB/c mice infected with $L$. major amastigotes and subjected to various drugs is shown in Fig. 4. The production of

Table 1 Model parameter statistics from the logistic regression of the five test extracts against promastigotes of $L$. major

\begin{tabular}{lll}
\hline Test drug & Model & Parameter significance \\
\hline A. indica & $\log (\rho / 1-\rho)=0.434+0.384 \times C-0.0008 \times C^{2}+0.0001 \times C^{3}$ & $\beta_{0}(0.0000) \beta_{1}(0.0000) \beta_{2}(0.0001) \beta_{3}(0.0026)$ \\
$R$. communis & $\log (\rho / 1-\rho)=0.225+0.324 \times C-0.0008 \times C^{2}+0.0008 \times C^{3}$ & $\beta_{0}(0.0000) \beta_{1}(0.0000) \beta_{2}(0.0002) \beta_{3}(0.0123)$ \\
Az + RC & $\log (\rho / 1-\rho)=0.125+0.454 \times C-0.0008 \times C^{2}+0.0011 \times C^{3}$ & $\beta_{0}(0.0000) \beta_{1}(0.0000) \beta_{2}(0.0003) \beta_{3}(0.0016)$ \\
AMB & $\log (\rho / 1-\rho)=0.015+0.684 \times C-0.0008 \times C^{2}+0.0004 \times C^{3}$ & $\beta_{0}(0.0000) \beta_{1}(0.0000) \beta_{2}(0.0004) \beta_{3}(0.0021)$ \\
Pentostam & $\log (\rho / 1-\rho)=0.012+0.724 \times C-0.0008 \times C^{2}+0.0014 \times C^{3}$ & $\beta_{0}(0.0000) \beta_{1}(0.0000) \beta_{2}(0.0001) \beta_{3}(0.0089)$ \\
\hline
\end{tabular}

$\mathrm{Az}+\mathrm{Rc}$, combination of $R$. communis and A. indica; $\mathrm{AMB}$, amphotericin $\mathrm{B}$ 
Table 2 Optimal efficacy, $I C_{90}$ and IC ${ }_{50}$ of test extracts against promastigote form of the parasite

\begin{tabular}{|c|c|c|c|c|c|c|c|}
\hline \multirow[t]{2}{*}{ Concentration $(\mu \mathrm{g} / \mathrm{mL})$} & \multicolumn{3}{|c|}{ Test drugs } & \multicolumn{2}{|l|}{ Controls } & \multicolumn{2}{|c|}{$\begin{array}{l}\text { Parameter and } \\
\text { statistics }\end{array}$} \\
\hline & $A z$ & Rc & $A z+R c$ & Pentostam & AMB & F value & P value \\
\hline Optimal efficacy (\%) & 78 & 61.5 & 91.2 & 96.5 & 98 & 26.654 & 0.002 \\
\hline Concentration at optimal efficacy & 43.5 & 69.5 & 55.2 & 30.4 & 40.2 & 9.257 & 0.012 \\
\hline $\mathrm{I}_{90}$ & - & - & 42 & 16.2 & 25.1 & 15.226 & 0.003 \\
\hline $\mathrm{IC}_{50}$ & 10.1 & 25.5 & 12.2 & 4.1 & 5.0 & 15.456 & 0.000 \\
\hline
\end{tabular}

$\mathrm{Az}$, A.indica; Rc, R. communis; $\mathrm{Az}+\mathrm{Rc}$, combination of A. indica and R. communis; $\mathrm{AMB}$, amphotericin $\mathrm{B}$

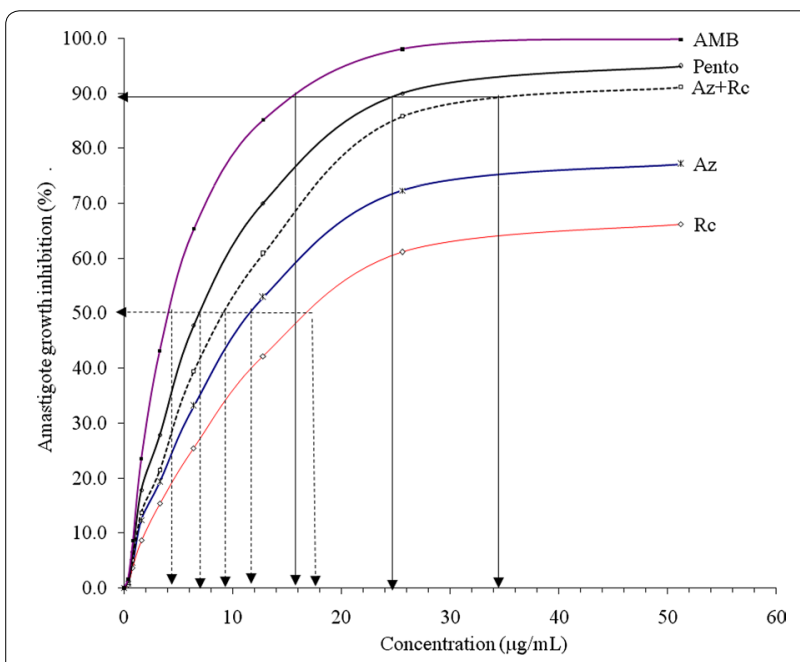

Fig. 3 Amastigote growth inhibition following treatments with the test extracts

Nitric Oxide decreased in the order $R$. communis $>A$. indica $+R$. communis $>A$. indica, hence treatment with combination therapy leads to more production of $\mathrm{NO}$ by the macrophages than that from standard drugs and monotherapy of $A$. indica. The Nitric Oxide produced by macrophages treated with Pentostam and Amphotericin $B$ were the lowest during the experiment. Infected macrophages treated with RPMI produced high amounts of nitric oxide.

The lesion sizes of BALB/c mice at the start of infection, during and the start of treatment with plant extracts and controls is shown in Fig. 5. There were no significant differences in development of lesion sizes in $\mathrm{BALB} / \mathrm{c}$ mice during the first 5 weeks post-infection with $L$. major $(p>0.05)$. Differences in lesion sizes between weeks 5 to week 10 were subjected to repeated measure ANOVA, which indicated that there were significant differences in lesion sizes among different treatments $(\mathrm{F}=d f=p=0.05)$. The lesion sizes of the untreated controls of BALB/c mice increased steadily after infection. Smallest lesion sizes occurred in BALB/c mice treated with combination therapy and amphotericin $\mathrm{B}$, which was slightly lower than BALB/c mice, treated Pentostam. BALB/c mice treated with monotherapies of $A$. indica or $R$. communis had larger lesion sizes. Treatment of BALB/c mice with $R$. communis resulted in the least reduction in lesion sizes among all the tested drugs post treatment. There was no significant difference between the combined therapy and Pentostam $(p>0.05)$; however the monotherapies showed lower activity than standard drugs.

Body weights, weight of spleen, spleen-somatic index and number of parasites in BALB/c infected with $L$. major under various treatments is shown in Table 5 . There were significant differences in the weight of spleen, splenosomatic index and number of parasites among treatments $(p<0.05)$. In $L$. major infected BALB/c mice, the spleen and spleno-somatic index was found to be significantly high when treatment was done using $R$. communis followed by $A$. indica. There was no significant difference between that of combination therapy of $A$. indica $+R$. communis and Pentostam. The index was highest in the untreated controls. BALB/c mice treated with Pentostam and those treated with Amphotericin B, the differences in spleen weight were not significant $(p>0.05)$. The number of parasites was also high in untreated controls, followed by those treated with $R$. communis and $A$. indica while combination treatment with $A$. indica $+R$. communis was lower. Nevertheless, treatment using amphotericin $\mathrm{B}$ and Pentostam resulted in the lowest numbers of parasites.

There were significant differences in the LDU of $L$. major parasites in BALB/c mice treated with monotherapies of $A$. indica, $R$. communis and a combination of $A$. indica $+R$. communis (ANOVA; $\mathrm{F}=d f=\mathrm{P}=0.05$ ). In L. major infected BALB/c mice, treatment with Pentostam, amphotericin $\mathrm{B}$ and combination therapy resulted in the lowest LDU. The LDU decreased in order of: $R$. communis $>A$. indica $>A$. indica $+R$. communis. There were no significant differences between LDU of BALB/c mice treated with Pentostam and that treated with 
Table 3 Model parameter statistics from the logistic regression of the plants extracts against amastigote of $L$. major

\begin{tabular}{lll}
\hline Test drug & Model & Parameter significance \\
\hline A. indica & $\log (\rho / 1-\rho)=0.434+0.384 \times C-0.0008 \times C^{2}+0.0001 \times C^{3}$ & $\beta_{0}(0.0000) \beta_{1}(0.0000) \beta_{2}(0.0001) \beta_{3}(0.0026)$ \\
$R$. communis & $\log (\rho / 1-\rho)=0.225+0.324 \times C-0.0008 \times C^{2}+0.0008 \times C^{3}$ & $\beta_{0}(0.0000) \beta_{1}(0.0000) \beta_{2}(0.0002) \beta_{3}(0.0123)$ \\
$A z+R C$ & $\log (\rho / 1-\rho)=0.125+0.454 \times C-0.0008 \times C^{2}+0.0011 \times C^{3}$ & $\beta_{0}(0.0000) \beta_{1}(0.0000) \beta_{2}(0.0003) \beta_{3}(0.0016)$ \\
AMB & $\log (\rho / 1-\rho)=0.015+0.684 \times C-0.0008 \times C^{2}+0.0004 \times C^{3}$ & $\beta_{0}(0.0000) \beta_{1}(0.0000) \beta_{2}(0.0004) \beta_{3}(0.0021)$ \\
Pentostam & $\log (\rho / 1-\rho)=0.012+0.724 \times C-0.0008 \times C^{2}+0.0014 \times C^{3}$ & $\beta_{0}(0.0000) \beta_{1}(0.0000) \beta_{2}(0.0001) \beta_{3}(0.0089)$ \\
\hline
\end{tabular}

$\mathrm{Az}+\mathrm{Rc}$, Combination of R. communis and A. indica; $\mathrm{AMB}$, amphotericin $\mathrm{B}$

Table 4 Optimal efficacy, IC ${ }_{90}$ and IC ${ }_{50}$ of test extracts against amastigote form of the parasite

\begin{tabular}{|c|c|c|c|c|c|c|c|}
\hline \multirow[t]{2}{*}{ Concentration $(\mu \mathrm{g} / \mathrm{mL})$} & \multicolumn{5}{|c|}{ Test drugs } & \multicolumn{2}{|c|}{ Parameter and statistics } \\
\hline & $A z$ & Rc & $A z+R c$ & Pento & AMB & F value & $p$ value \\
\hline Optimal efficacy (\%) & 72 & 59.5 & 88 & 98 & 92 & 17.311 & 0.002 \\
\hline Concentration at optimal efficacy & 25.5 & 28.2 & 35.1 & 25.2 & 34.5 & 9.212 & 0.001 \\
\hline$I_{90}$ & - & - & 34.5 & 15.5 & 24.5 & 19.221 & 0.001 \\
\hline$I_{50}$ & 11.5 & 16.5 & 9.0 & 6.5 & 4.5 & 12.489 & 0.000 \\
\hline
\end{tabular}

$\mathrm{Az}$, A. indica; Rc: R. communis; $A z+R c$ combination of $A$. indica and R. communis; Pento, pentostam; AMB, amphotericin $\mathrm{B}$

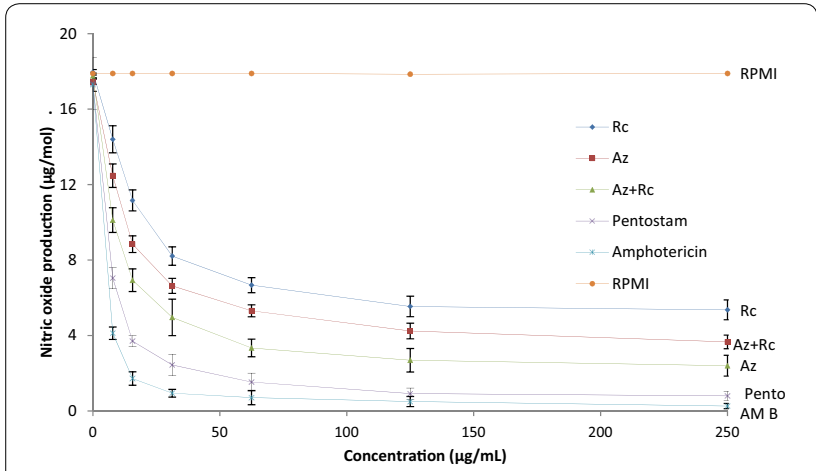

Fig. 4 Nitric oxide production in the macrophages of BALB/C infected mice infected with L. major and subjected to different treatments by various test extracts

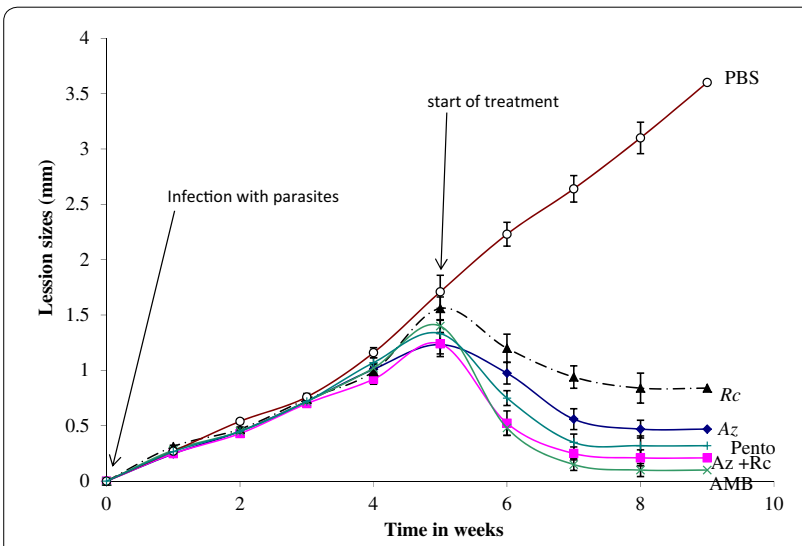

Fig. 5 Effect of mono and combination therapy on L. majorlesion development in BALB/C mice combination therapy $(p<0.05)$. The LDU of L. major parasite in $\mathrm{BALB} / \mathrm{c}$ mice infected with $L$. major receiving various treatments is shown in Fig. 6.

\section{Discussion}

Chemotherapy against leishmaniasis is mainly based on the antimonial compounds, sodium stibogluconate and meglumine antimoniate (glucantine). The mode of action of antimonials is poorly understood, and -their toxicity causes serious side effects that often result in patients deserting treatment. Furthermore, there is a worldwide escalating frequency of chemo-resistance to antimonials, thus, affordable alternative drugs against leishmaniasis are momentously needed. This study set out to determine the antileishmanial activities of $A$. indica and $R$. communis used in combination and independently against L. major infection in susceptible BALB/c mice. A combination therapy of $A$. indica and $R$. communis was very efficient in decreasing lesions in infected BALB/c mice. This antileishmanial activity was compared to that of the standard drugs. The combination therapy was also highly cytotoxic to the promastigotes and amastigotes in vitro while nontoxic to the macrophages and the VeroE6 cells. In vivo, basing on the behaviour of the mice, the extracts were well tolerated during the treatment period.

The monotherapies were initially tested for their antileishmanial activity and the results of this study showed that $A$. indica was of higher potency than $R$. communis however their cytotoxicity against peritoneal macrophages as well as veroE6 cells was still lower than that of the standard drugs. The methanolic extract of $R$. communis reduced L. major lesion development, as well 
Table 5 Body weight, weight of spleen, spleno-somatic index and number of parasites in BALB/c mice following various treatments

\begin{tabular}{|c|c|c|c|c|}
\hline Treatment & Body weight & Weight of spleen & Spleno-somatic index & No of parasites \\
\hline$A z$ & $22.11 \pm 0.54$ & $0.18 \pm 0.021^{c}$ & $0.84 \pm 0.10^{c}$ & $37.3 \pm 6.4^{c}$ \\
\hline Rc & $21.78 \pm 0.89$ & $0.23 \pm 0.021^{b}$ & $1.04 \pm 0.08^{b}$ & $58.4 \pm 9.8^{b}$ \\
\hline$A z+R c$ & $20.50 \pm 0.45$ & $0.15 \pm 0.006^{\mathrm{a}}$ & $0.73 \pm 0.02^{a}$ & $26.4 \pm 0.7^{\mathrm{a}}$ \\
\hline Amphotericin B & $21.00 \pm 1.00$ & $0.13 \pm 0.005^{\mathrm{a}}$ & $0.74 \pm 0.06^{\mathrm{a}}$ & $25.7 \pm 0.5^{\mathrm{a}}$ \\
\hline Pentostam & $21.00 \pm 0.58$ & $0.14 \pm 0.010^{a}$ & $0.75 \pm 0.07^{a}$ & $26.1 \pm 0.4^{\mathrm{a}}$ \\
\hline PBS & $21.00 \pm 1.73$ & $0.37 \pm 0.014^{d}$ & $1.83 \pm 0.21^{d}$ & $145.7 \pm 6.7^{d}$ \\
\hline \multicolumn{5}{|l|}{ ANOVA } \\
\hline F & 2.1332 & 35.255 & 71.214 & 46.987 \\
\hline$d f$ & 5 & 5 & 5 & 5 \\
\hline$P$ & 0.3245 & 0.0001 & 0.0000 & 0.0000 \\
\hline
\end{tabular}

Means in the same column followed by the same superscript show no significant difference between them

$\mathrm{Az}$, A. indica; Rc, R. communis; Az + Rc, A. indica and R. communis (combination therapy); PBS, phosphate buffered saline (negative control); Pentostam, standard drug (positive control); Amphotericin B, standard drug (positive control)

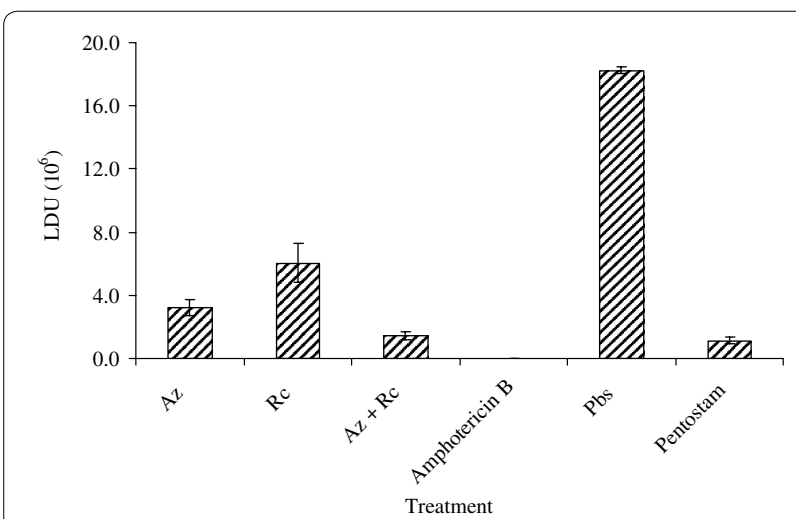

Fig. 6 The LDU of L. major parasite in spleen of BALB/C mice infected with L. major receiving various treatments

as parasite loads in the spleen; this suggests the extract was successful in inhibiting $L$. major parasite growth. Though the activity was lower than that of the standard drugs, this may be attributed to the fact that the extracts in this study were used in their crude form. Studies have shown that isolation of active ingredients of plant extracts improves their potency [43]. If the bioactive phytochemical compounds of $R$. communis that are targeted at $L$. major are isolated while eliminating those that are cytotoxic to body cells it may give different results. This current study is consistent with earlier studies [35, 44] that show potential antimicrobial effect of $R$. communis with evidence of in vivo and in vitro activities of the plant extracts.

Treatment with $A$. indica extracts also exhibited marked reduction in lesion development and parasite load in vitro and in vivo. It is more active against promastigotes than amastigotes but causes production of very low levels of NO from macrophages than that produced by other test compounds. This indicates its low induction activity on peritoneal macrophages for production of NO, than that observed in $R$. communis treatment. Its activity is however better than the standard drugs in term of their cytotoxicity to the macrophages and veroE6 cells. It also fits the logistic regression model for drug administration; which shows its high potential as a candidate for treatment of the L. major infection [42]. These findings agree with earlier studies using the same extracts against parasitic organisms of trypanosomatidae [43, 45] and recent work on L. donovani [16].

The significant decrease in the lesion sizes in the combined therapy is indicative of the occurrence of a synergistic mechanism between the drug combinations. The two extracts have different modes of action and their combination tends to improve their antileishmanial activity. Moreover, the progression of the splenomegally and the increase of the splenic load were found to be significantly lower in treated mice than in untreated controls, demonstrating parasite suppression and the inhibition of parasite growth. The spleen is a major site of Leishmania multiplication in the natural infection in susceptible hosts. In BALB/c mice, the splenic parasite burden is initially quite low, but it increases steadily for at least 3 months, and unlike the hepatic burden, it does not decline spontaneously without treatment [6]. The splenic efficacy of the test compounds should be emphasized, since until recently splenectomy was performed as the last recourse for cases of antimony resistant leishmaniasis. It is evident from the monotherapy results that treatment with either $A$. indica or $R$ communis resulted in parasite inhibition but at a lower level than for combination therapy. It can therefore be concluded that 
administration of the combination of drugs is effective and superior to individual drugs. The synergism shown with the combined drugs brings us to the concept of structure-function approach in fighting leishmaniasis. The effect of combination therapy of $A$. Indica and $R$. communis may be due to complementarity between the two extracts. The standard drugs are known to exhibit cytotoxicity to the cells and cause inflammation at the site of infusion Combination therapy also leads to production of more NO by the macrophages than is seen in the monotherapy of $A$. Indica, thus suggests that the latter treatment up-regulates production of $\mathrm{NO}$ by the macrophages and this may be one of the ways in which the parasites are eliminated from the macrophages, Considering that the efficacy towards promastigotes is higher than that against amastigotes, the combined therapy may also have direct cytotoxicity toward the parasites. The penetration of the test compounds into macrophages is hence comparable to that of amphotericin $B$ and poorer than that of Pentostam. Pentostam has been reported to have better action against amastigotes due to its high penetration ability into the macrophages. However, the efficacy of the combination therapy may still be low compared to the standard drugs except for good LDU data, because the extracts were used in their crude form. Using a combination therapy and administration through intraperitoneal route therefore may have the potential as a good intervention to treatment of cutaneous leishmaniasis in murine models.

Macrophages, the target cells in therapy of leishmaniasis play an important role in the immunological control of intracellular parasites through the production of cytokines and oxygen metabolites [46]. One of the main mechanisms is the up-regulation of nitric oxide inside the macrophages, which is an effective mediator in killing amastigotes [47]. In this study combination therapy caused a slight increase in the NO produced by the macrophages, a slight improvement from that produced by the monotherapies which suggests that it may be one of the modes of action of the extracts but not the only mechanism involved in parasite elimination. This is not seen among the standard drugs. However it is consistent with previous studies that $R$. communis up-regulates production of NO, though in small quantity in the macrophages. A. indica may have other mechanism by which it causes its anti-parasitic activity apart from just increasing the amount of NO. This study is in tandem with previous studies that dispute the fact that $A$. indica is capable of activating the immune system to induce production of interferon-gamma (IFN- $\gamma$ ) and tumor necrosis factoralpha (TNF- $\alpha$ ) [48], cytokines that act in synergy in the activation of macrophages to produce nitric oxide and control the infection by Leishmania [49]. It is however in agreement with the fact that $A$. indica does not cause up-regulation of NO in the macrophages [43]. The combined therapy however, has a synergy of action leading to its activity, which causes immunomodulatory action. This may have been a point where synergism is well demonstrated by the combined therapy.

The effect of the drugs on the VeroE6 cells in vitro shows that the toxicity of the two extracts is still in the manageable range, this also improves in combination. This was also observed in the in vivo experiments for none of the mice died during the experimental period and there was no marked weight reduction or ill health among the treated mice. This may be due to the fact that for $R$. communis, the leaves are less toxic, have lesser ricin, than the fruits which has been documented to be very toxic $[43,50,51]$. A. indica too was only cytotoxic to the parasites but less toxic to the veroE6 cells and the macrophages. The extracts studied showed excellent antileishmanial activity that was unrelated to toxicity, which guarantees safety to the macrophages and specificity to the parasite which is consistent with studies by Nwaka and Hudson [52]. Combining the two drugs does not seem to increase toxicity to veroE6 cells and peritoneal macrophages but improves their potency against the amastigotes and promastigotes. This gives a good base for further investigation to access whether these extracts could become valid candidates for drug development.

There are some limitations associated with this study. First, the in vivo treatment majorly focused on intraperitoneal mode of administration hence other modes of treatment that is intravenous and subcutaneous should also be explored. To confirm on the non-toxic nature of the plant extracts, the effect that various factors such as the growth stage and maturity of the plant, regional variations (where the plant is growing) should be looked into. Leishmaniasis associated cytokine profiles (interferongamma (IFN- $\gamma$ ) and tumor necrosis factor-alpha (TNF- $\alpha$ among others) were not analyzed. The evaluation can help give more insight on the synergistic effect of the extracts.

\section{Conclusion}

Results from this study indicates that both plant extracts have antileishmanial activity. The two medicinal extracts when used in combination have synergistic effects in treatment of leishmaniasis. Results of this study also indicated that the test plant extracts had relatively higher cytotoxicity to parasites than the host cells at concentrations used to inhibit growth of the parasites. Based on the observed antileishmanial activity and low or absence of cytotoxicity on the host cells, it is suggested that a combination therapy of $R$. communis and $A$. indica be used for bioassay-guided 
fractionation, isolation of bioactive compounds and their fortification, which could serve as new drug lead structures. Isolation of bioactive components can also be carried out with the intention of removal of components with strong cytotoxic effects as well as identify and mark those active compounds for antileishmanial activity.

\section{Authors' contributions}

This work was carried out in collaboration between all authors. BNJ, CKW, COA and $\mathrm{JM}$ conceived and designed the study. BNJ, CKW, SM and RN performed the experiments. BNJ, JM, COA, CKC, CKW and JI contributed reagents/materials/analysis tools and logistical support. BNJ and CKW analyzed the data. All the authors participated in drafting and revising the manuscript. All authors read and approved the final manuscript.

\section{Author details \\ ${ }^{1}$ Department of Biological Science (Parasitology), University of Eldoret, P.O Box 1125-30100, Eldoret, Kenya. ${ }^{2}$ Centre for Biotechnology Research and Development (CBRD), Kenya Medical Research Institute (KEMRI), P.O Box 54840-00200, Nairobi, Kenya. ${ }^{3}$ Zoology Department, Jomo Kenyatta University of Agriculture and Technology (JKUAT), P.O. Box 62000-00200, Nairobi, Kenya. ${ }^{4}$ Institute of Tropical Medicine and Infectious Diseases-KEMRI (ITROMID-KEMRI), Jomo Kenyatta University of Agriculture and Technology (JKUAT), P.O. Box 62000-00200, Nairobi, Kenya. ${ }^{5}$ University of Kabianga, P.O. Box 2030-20200, Kericho, Kenya. ${ }^{6}$ African Population and Health Research Center (APHRC), P.O. Box 10787-00100, Nairobi, Kenya. ${ }^{7}$ Applied Science Department, Sigalagala National Polytechnic, P. O. Box 2966, Kakamega, Kenya. ${ }^{8}$ Department of Medical Laboratory Sciences, Masinde Muliro University of Science and Technology, P.O Box 190, Kakamega 50100, Kenya.}

\section{Acknowledgements}

The authors thank Mr. Lucas Ogutu of Kenya Medical Research Institute (KEMRI) for rearing the animals used in this study. We thank Dr Oyoo-Okoth Elijah, for the technical assistance during data analysis support in the different facets of this study.

\section{Competing interests}

The authors declare that they have no competing interests.

Received: 10 February 2015 Accepted: 19 October 2015 Published online: 05 November 2015

\section{References}

1. Alvar J, Yactayo S, Bern C. Leishmaniasis and poverty. Trends Parasitol. 2006;22(12):552-7.

2. Chappuis F, Sundar S, Hailu A, Ghalib H, Rijal S, Peeling RW, Alvar J, Boelaert M. Visceral leishmaniasis: what are the needs for diagnosis, treatment and control? Nat Rev Microbiol. 2007;5(11):873-82.

3. WHO. Control of leishmaniasis report by secretariat. In: Sixtieth world health assembly A60/10. Provsion agenda item 12.3. 2007.

4. Alexander B, Maroli M. Control of phlebotomine sandflies. Med Vet Entomol. 2003;17(1):1-18.

5. Desjeux P. Leishmaniasis: current situation and new perspectives. Comp Immunol Microbiol Infect Dis. 2004;27(5):305-18.

6. Croft SL, Seifert K, Duchene M. Antiprotozoal activities of phospholipid analogues. Mol Biochem Parasitol. 2003;126(2):165-72.

7. Gauvreau D, Roy C, Tom FQ, Lu H, Miegueu P, Richard D, Song WC, Stover C, Cianflone K. A new effector of lipid metabolism: complement factor properdin. Mol Immunol. 2012;51(1):73-81.

8. Croft SL, Sundar S, Fairlamb AH. Drug resistance in leishmaniasis. Clin Microbiol Rev. 2006;19(1):111-26.

9. Collon S. Conflict and kala-azar: determinants of adverse outcomes of kala-azar among patients in southern Sudan. Clin Infect Dis. 2004;38:612-9.
10. Seaman J, Mercer AJ, Sondorp HE, Herwaldt BL. Epidemic visceral leishmaniasis in southern Sudan: treatment of severely debilitated patients under wartime conditions and with limited resources. Ann Intern Med. 2006;124:664-72.

11. Sundar S, More DK, Singh MK, Singh VP, Sharma S, Makharia A, Kumar PC, Murray HW. Failure of pentavalent antimony in visceral leishmaniasis in India: report from the center of the Indian epidemic. Clin Infect Dis. 2000;31(4):1104-7.

12. Yamey GaTE. The world's most neglected diseases. BMJ 2000;325:176-7

13. Gupta RS, Bhatnager AK, Joshi YC, Sharma R, Sharma A. Effects of plumieride, an iridoid on spermatogenesis in male albino rats. Phytomedicine. 2004;11(2-3):169-74.

14. Oyeewole OI, Owoseni AA, Faboro EO. Studies on medicinal and toxicological properties of Cajanus cajan, R. communis and Thymus vulgaris leaf extracts. J Med Plant Res. 2010;4:2004-8.

15. Lomash V, Parihar SK, Jain NK, Katiyar AK. Effect of Solanum nigrum and Ricinus communis extracts on histamine and carrageenan-induced inflammation in the chicken skin. Cell Mol Biol (Noisy-le-grand). 2010;56(Suppl):OL1239-51.

16. Dayakar A, Chandrasekaran S, Veronica J, Sundar S, Maurya R. In vitro and in vivo evaluation of anti-leishmanial and immunomodulatory activity of Neem leaf extract in Leishmania donovani infection. Exp Parasitol. 2015;153:45-54

17. Bent S, Ko R. Commonly used herbal medicines in the United States: a review. Am J Med. 2004;116(7):478-85.

18. Karani L, Tolo F, Karanja S, Khayeka C. Safety and efficacy of Prunus africana and Warburgia ugandensis against induced asthma in BALB/C Mice. Eur J Med Plants. 2013;3(3):345-68.

19. Karani LW, Tolo FM, Karanja SM, Khayeka-Wandabwa C. Safety of Prunus africana and Warburgia ugandensis in asthma treatment. South Afr J Bot. 2013;88:183-90.

20. Rana M, Dhamija H, Prashar B, Sharma S. Ricinus communis L.-a review. Int J Pharm Tech Res. 2012;4(4):1706-11.

21. Kigondu EV, Rukunga GM, Keriko JM, Tonui WK, Gathirwa JW, Kirira PG, Irungu B, Ingonga JM, Ndiege IO. Anti-parasitic activity and cytotoxicity of selected medicinal plants from Kenya. J Ethnopharmacol. 2009;123(3):504-9.

22. Idson B. Percutaneous absorption. J Pharm Sci. 1975;64(6):901-24.

23. Beach R, Kiilu G, Hendricks L, Oster C, Leeuwenburg J. Cutaneous leishmaniasis in Kenya: transmission of Leishmania major to man by the bite of a naturally infected Phlebotomus duboscai. Trans R Soc Trop Med Hyg. 1984;78(6):747-51.

24. Hendricks L, Wright N. Diagnosis of cutaneous leishmaniasis by in vitro cultivation of saline aspirates in Schneider's Drosophila Medium. Am J Trop Med Hyg. 1979;28(6):962-4.

25. Kimber CD, Evans DA, Robinson BL, Peters W. Control of yeast contamination with 5-fluorocytosine in the in vitro cultivation of Leishmania spp. Ann Trop Med Parasitol. 1981;75(4):453-4.

26. Mosmann T. Rapid colorimetric assay for cellular growth and survival: application to proliferation and cytotoxicity assays. J Immunol Methods. 1983;65(1-2):55-63.

27. Wang X, Ge J, Wang K, Qian J, Zou Y. Evaluation of MTT assay for measurement of emodin-induced cytotoxicity. Assay Drug Dev Technol. 2006;4(2):203-7.

28. Vodovotz Y, Bogdan C, Paik J, Xie QW, Nathan C. Mechanisms of suppression of macrophage nitric oxide release by transforming growth factor beta. J Exp Med. 1993;178(2):605-13.

29. Bogdan C, Vodovotz Y, Paik J, Xie QW, Nathan C. Mechanism of suppression of nitric oxide synthase expression by interleukin-4 in primary mouse macrophages. J Leukoc Biol. 1994;55(2):227-33.

30. Berman JD, Lee LS. Activity of antileishmanial agents against amastigotes in human monocyte-derived macrophages and in mouse peritoneal macrophages. J Parasitol. 1984;70(2):220-5.

31. Delorenzi JC, Attias M, Gattass CR, Andrade M, Rezende C, da Cunha Pinto A, Henriques AT, Bou-Habib DC, Saraiva EM. Antileishmanial activity of an indole alkaloid from Peschiera australis. Antimicrob Agents Chemother. 2001;45(5):1349-54

32. Bradley DJ. Regulation of Leishmania populations within the host. II. genetic control of acute susceptibility of mice to Leishmania donovani infection. Clin Exp Immunol. 1977;30(1):130-40. 
33. Mead R, editor. The design of experiments. New York: Cambridge University Press; 1988.

34. Khayeka-Wandabwa C, Kutima H, Nyambati VC, Ingonga J, Oyoo-Okoth E, Karani L, Jumba B, Githuku K, Anjili CO. Combination therapy using Pentostam and Praziquantel improves lesion healing and parasite resolution in BALB/C mice co-infected with Leishmania major and Schistosoma mansoni. Parasit Vectors. 2013;6:244

35. Okech BA, Irungu LW, Anjili CO, Munyua JK, Njagi ENM, Rukunga G. The in vitro activity of total aqueous and ethanol leaf extracts of Ricinus communis on Leishmania major promastigotes. Kenya J Sci. 2006;13(1):1-4.

36. Wabwoba BW, Anjili CO, Ngeiywa MM, Ngure PK, Kigondu EM, Ingonga J, Makwali J. Experimental chemotherapy with Allium sativum (Liliaceae) methanolic extract in rodents infected with Leishmania major and Leishmania donovani. J Vector Borne Dis. 2010;47:160-7.

37. La Flamme AC, Scott P, Pearce EJ. Schistosomiasis delays lesion resolution during Leishmania major infection by imparing parasite killing by macrophages. Parasite Immunol. 2002;24:339-45.

38. Nolan TJ, Farrell JP. Experimental infections of the multimammate rat (Mastomys natalensis) with Leishmania donovani and Leishmania major. Am J Trop Med Hyg. 1987;36(2):264-9.

39. Chaiworaporn R, Maneerat Y, Rojekittikhun W, Ramasoota P, Janecharut T, Matsuda H, Kitikoon V. Therapeutic effect of subcurative dose praziquantel on Schistosoma mansoni infected mice and resistance to challenge infection after treatment. Southeast Asian J Trop Med Public Health. 2005;36(4):846-52.

40. Engwerda CR, Murphy ML, Cotterell SE, Smelt SC, Kaye PM. Neutralization of IL-12 demonstrates the existence of discrete organ-specific phases in the control of Leishmania donovani. Eur J Immunol. 1998;28(2):669-80.

41. Zar JH, editor. Biostatistical analysis. 4th ed. New Jersey: Englewood Cliffs; 1999
42. Agresti A, editor. Logistic regression models. New York: Wiley-Interscience; 1990

43. Carneiro SM, Carvalho FA, Santana LC, Sousa AP, Neto JM, Chaves MH. The cytotoxic and antileishmanial activity of extracts and fractions of leaves and fruits of Azadirachta indica (A Juss.). Biol Res. 2012;45:111-6.

44. Zarai Z, BenChobba I, BenMansour R, Bekir A, Gharsallah N, Kadri A. Essential oil of the leaves of Ricinus communis L.: in vitro cytotoxicity and antimicrobial properties. Lipids Health Dis. 2012;11:102.

45. Anthony JP, Fyfe L, Smith H. Plant active components-a resource for antiparasitic agents? Trends Parasitol. 2005;21(10):462-8.

46. Balaraman S, Tewary P, Singh VK, Madhubala R. Leishmania donovani induces interferon regulatory factor in murine macrophages: a host defense response. Biochem Biophys Res Commun. 2004;317(2):639-47.

47. Mauel J, Ransijn A. Leishmania spp. Mechanisms of toxicity of nitrogen oxidation products. Exp Parasitol. 1997:87:98-111.

48. Mukherjee S, Garg S, Talwar GP. Early post implantation contraceptive effects of a purified fraction of neem (Azadirachta indica) seeds, given orally in rats: possible mechanisms involved. J Ethnopharmacol. 1999;67(3):287-96.

49. Bogdan C, Gessner A, Solbach W, Rollinghoff M. Invasion, control and persistence of Leishmania parasites. Curr Opin Immunol. 1996;8(4):517-25.

50. Okech BA, Irungu LW, Anjili CO, Munyua JK, Njagi ENM, Rukunga G. The in vitro activity of total aqueous and ethanol leaf extracts of Ricinus communis on Leishmania major promastigotes. Kenya J Sci Series B. 2006;13(1):1-4.

51. Manpreet HD, Bharat $P$, Shivani S. Ricinus communis L. - a review. Int J Pharm Tech Res. 2012;4(4):1706-11.

52. Nwaka S, Hudson A. Innovative lead discovery strategies for tropical diseases. Nat Rev Drug Discov. 2006:5(11):941-55.

\section{Submit your next manuscript to BioMed Central and take full advantage of:}

- Convenient online submission

- Thorough peer review

- No space constraints or color figure charges

- Immediate publication on acceptance

- Inclusion in PubMed, CAS, Scopus and Google Scholar

- Research which is freely available for redistribution

Submit your manuscript at

www.biomedcentral.com/submit

C Biomed Central 